\title{
La nueva gramática democrática frente a la integración autónoma latinoamericana y caribeña
}

Jaime Antonio Preciado Coronado*

Resumen: La "democratización liberal y de mercado", se propone amortiguar la crisis global y sistémica por la que atraviesa América Latina, región cuya memoria histórica registra traumáticos procesos de autoritarismo de mercado sobre sus sistemas políticos. La democracia procedimental y los sistemas multipartidistas monopolizan la representación, pretendiendo convertirse en antídoto contra el autoritarismo y fuente de un futuro desarrollo prominente. Mientras tanto, el discurso neoliberal que enaltecía las ventajas del libre mercado, la desregulación, las privatizaciones y el Estado mínimo, de acuerdo al Consenso de Washington, estableció este modelo ideológico como conductor de la integración, y condicionante para la estabilidad democrática y macroeconómica. Sin embargo, la democracia liberal-procedimental en la región, asociada al proceso de integración neoliberal, produjo un conflictivo triángulo Estado-Sociedad-Mercado, donde la imposición de un modelo de organización política y un sistema de valores homogéneo anglo-eurocéntrico, promovido como democracia global, fue el discurso dominante. Ante la desigualdad y la exclusión producto de ese modelo, emergen propuestas post-neoliberales orientadas a redibujar la integración democrática en la pizarra latinoamericana. Desde los movimientos sociales, surgen proyectos políticos con una nueva gramática democrática de resistencia, y reconocimiento de agendas sociales relacionadas con la integración autónoma latinoamericana.

Palabras clave: democracia; integración regional; autonomía; movimientos sociales.

\section{Introducción}

A unque la democracia como forma de gobierno cobra un papel protagónico en la escala de los Estados nacionales, hay nuevas realidades que muestran la importancia de otras escalas que entran en juego. Desde la escala de la llamada gobernanza global, hasta las experiencias de gobiernos locales que se fundan sobre formatos democráticos directos, que se ejercen en la vida cotidiana, pasando por transformaciones de los regímenes democráticos nacionales, recobran visibilidad los desafíos que presentan los procesos de integración supranacional regional para el avance y la consolidación democrática.

Podemos distinguir dos grandes esquemas de integración que se debaten mundialmente: la integración regional por bloques que comparten intereses comerciales, cada vez más vinculados a las reformas de mercado, y la integración regional comunitaria, que apunta hacia la multidimensionalidad de lo social desde aspectos económicos, políticos y culturales. No obstante que ambos formatos apelan a la democracia como

\author{
* Profesor \\ Investigador de \\ la Universidad \\ de Guadalajara, \\ México. Profesor \\ Invitado en el Iteso, \\ Universidad Jesuita \\ de Guadalajara, \\ agradece el apoyo \\ de Luis Adrián \\ Guzmán Dávila. \\ <japreco@hotmail. \\ coms.
}


base de sustentación de sus regímenes, de sus gobiernos y como marco condicionante de sus relaciones internacionales, cabe preguntar si los valores democráticos, los regímenes y las prácticas sociales participativas son potenciados en general por los procesos de integración y en particular sobre lo que aportan u obstaculizan cada uno de los esquemas de integración.

El contexto de la crisis global y sistémica, profundizado a partir de 2008 desde el epicentro estadounidense, enmarca el debate democrático que se tratará en este trabajo. El modelo de gobernanza global centrado en las instituciones monetarias y financieras internacionales de la posguerra fracasó y los Estados nacionales se debilitan como potencia pública capaz de democratizar las relaciones entre mercado, gobierno y sociedad, con lo que la democracia nacional se ha relegado a sus aspectos procedimentales, pues la soberanía popular está excluida de los asuntos económicos de todos y la "democracia de pocos" (González Casanova, 2002), impone la minimización del Estado en lo social, y la maximización para el traslado de recursos financieros hacia el Estado Corporación mundial-local.

¿Se podría identificar entonces la emergencia de un modelo de gobernanza supranacional-regional que permita superar las limitaciones globales? En el campo internacional, el desplazamiento de la lucha por el poder del G-8 hacia el G-20, tiende a configurar una suerte de "geopolítica de las panregiones", en la cual cada continente cuenta con una potencia organizadora y con países semiperiféricos, calificados como economías emergentes, que buscan erigirse en potencias regionales, pero que son imprescindibles para los países centrales. De ahí que el proceso de integración supranacional regional, sea comandado por las potencias del Norte, de los países centrales, mientras que los recursos humanos, financieros, naturales del Sur, aparecen como objeto de disputa entre los países del G-8, que invitan a tratados comerciales o acuerdos de integración dentro de una matriz Norte-Sur.

\section{Democracia e integración: desafíos mutuos}

El caso latinoamericano ayuda a esclarecer la correlación entre democracia e integración, pues la consolidación democrática de gobiernos nacionales, caracterizados de izquierda, que vive esta región desde finales de los años 90, está aportando nuevas realidades al proceso de integración regional. A diferencia de esquemas de integración Norte Sur, que son preponderantes a la escala mundial, en Latinoamérica emergen con fuerza nuevos formatos de integración Sur-Sur. Ello es el resultado de esfuerzos por vincular la democratización nacional, con exigencias que buscan incidir en la democratización de las relaciones internacionales, desde la recuperación y defensa de una autonomía capaz de acompasar lo nacional, lo supranacional regional y un nuevo 
modelo de gobernanza global. En Latinoamérica, se busca: revalorizar la capacidad reguladora del Estado; mayor capacidad de negociación frente a la apertura y la liberalización comercial y financiera; cuestionar el modelo económico dominante; situar el tema de la justicia social y la redistribución del ingreso y actualizar el pacto social mediante nuevas relaciones entre movimientos sociales y gobierno. En suma, lo que Emir Sader (2013) Ilama post-neoliberalismo.

No obstante esas fuerzas fundadoras de una nueva gramática democrática, en Latinoamérica coexisten dos líneas maestras que orientan su integración regional: 1) los esquemas de corte neoliberal, que responden a la matriz Norte-Sur (Tratado de Libre Comercio de América del Norte (TLCAN), Central America Free Trade Agreement + Dominican Republic (Cafta+DR, por sus siglas en inglés); Alianza del Pacífico, iniciativa de Perú, México, Colombia y Chile, asociada con la Trans Pacific Partnership (TPP), que Estados Unidos promueve con sus aliados para combatir el poderío de los países asiáticos en el Pacífico. Lo cual se complementa con la Alianza Trasatlántica de Comercio e Inversión (TTIP, por su sigla en inglés), que promueven conjuntamente la Unión Europea y Estados Unidos, con el mismo objetivo de disputar la influencia asiática en el mercado mundial. 2) En contraparte, nuestra región cuenta con esquemas de inspiración post-neoliberal Sur-Sur, como son los casos de la convergencia entre MercosurComunidad Andina (CAN), y la Unión de Naciones Suramericanas (Unasur), e incluso aparecen bloques post-neoliberales con estrategias contrahegemónicas deliberadas, como es el caso de la Alianza Bolivariana para los Pueblos de Nuestra América - Tratados Comerciales entre los Pueblos (Alba-TCP).

Mientras que en los formatos de integración neoliberal predomina el paradigma de una democracia elitista, sustentada en coalición con un polo tecnocrático, en los esquemas post-neoliberales se acrecientan experiencias fundadas sobre la democracia participativa, en la que empieza a prefigurarse una democracia comunitaria de base étnica-nacional, la cual representa una nueva coalición de intereses pluriclasistas, que busca procesar el conflicto social sobre bases deliberativas e incluyentes.

La integración neoliberal, comandada por Estados Unidos, acude al imaginario (neo) panamericanista cuya expansión camina sobre tres pilares que se establecen como condicionantes: la democracia liberal occidental centrada en el Estado-nación; la adopción de reformas de mercado que fomenten el modelo orientado a la exportación, la apertura, la privatización y la liberalización económicas; y la geoestrategia de seguridad estadounidense compartida.

Desde otra perspectiva, el imaginario latinoamericano es fruto de tradiciones históricas autonómicas que, sin embargo, son asumidas de manera heterogénea; en unos casos, desde la retórica nacionalista y prácticas pragmáticas en los hechos, en otros 
casos, desde la inspiración de un pensamiento orientado a la crítica a la colonialidad del poder (Quijano, 2000, pág. 246), mediante una nueva gramática democrática que vuelca su mirada al pensamiento bolivariano, martiano y el de los pueblos originarios. Una integración a múltiples velocidades donde se distinguen, con tensiones diversas, la integración del conjunto latinoamericano, como ha sido recientemente el caso de la Comunidad de Estados Latinoamericanos y del Caribe (Celac) y por otra parte, avances sustantivos en América del Sur, que incluso podrían caracterizarse como un sur-latinoamericanismo, que camina más rápido y consolida de manera más profunda los vínculos de sur a sur.

Los desafíos que la democracia plantea a la integración, se ubican tanto en el ámbito del Estado nacional, como de la nueva institucionalidad supranacional que está emergiendo al calor de la integración y las demandas de participación social respectivas. Lo cual desemboca en un marco de tensión entre reforma del Estado y Reformas de mercado, expresadas en términos constitucionales, que han fundado nuevos pactos sociales que buscan compaginar una configuración plurinacional e intercultural. Uno de los aportes más significativos de esta nueva gramática democrática, es el debate sobre el modelo de desarrollo desde la originalidad que ofrece el Estado y los principios del Buen Vivir (Sumak Kawsay). Escenario polémico que se propone el empoderamiento de la ciudadanía, desde el reforzamiento étnico de pueblos originarios, y su apertura frente a la agenda social que enarbolan los movimientos sociales, no sin dificultades para conciliar su implantación en una matriz estatal nacional que sea capaz de articular esas experiencias con la construcción de espacios supranacionales.

En los procesos de integración regional que vive Latinoamérica, aumenta la tensión entre lo instituyente, que portan los movimientos sociales demandantes de reconocimiento y derechos no incorporados al mundo de las instituciones, y lo instituido, propio de la supranacionalidad regional, como parlamentos, esquemas de gobernabilidad eficaces y eficientes, el reconocimiento de las autonomías étnicas y subregionales. Se trata de repensar la democracia, como paradigma de gobierno y de participación ciudadana, desde la interculturalidad, la pluralidad étnico-nacional fundadora de un nuevo Estado nacional, y del reconocimiento de nuevas instancias supranacionales que requieren estar sujetas a un proceso democratizador en el que la política internacional sea sensible a los registros de-coloniales y la autonomía. 


\section{Interpretar la crisis desde la democracia}

No hay acuerdo sobre el carácter y la naturaleza de la crisis. Se pueden distinguir dos marcos esenciales sobre su interpretación. Para el establishment y los think tanks de orientación neoliberal, se trata de una crisis profunda pero superable, en la medida que se revisen y adapten los preceptos surgidos de la racionalidad económica instrumental: corregir en lo que cabe el Consenso de Washington (Williamson, 1990 y 2003) - para el caso latinoamericano -, convocar a la austeridad de las finanzas públicas y eventualmente de las capas privilegiadas en el caso de directores de empresas oligopólicas y, sobre todo, mantener a toda costa la acumulación capitalista mediante el control del salario y, paradójicamente, la elevación de la competitividad y de la productividad. El paradigma "democrático" requerido para salir de la crisis es el de la formalización del espacio representativo, en el que se concede que el polo tecnocrático de la coalición política del gobierno en turno, no sea sometido por instancias legislativas ni pueda ser cuestionado por movimiento social alguno.

Desde esa interpretación, el regionalismo es decisivo por su potencial dinamizador del mercado mundial. De ahí resulta una integración eminentemente comercial, aunque cada vez más demandante de acuerdos relativos a la inversión y a la subordinación de las economías nacionales del mundo financiero. La democracia se reduce así al ámbito electoral, al traspaso periódico y pacífico del gobierno mediante elecciones supuestamente libres: un ciudadano, un voto, que delega todos los asuntos de interés público en los representantes "populares", preferentemente el poder Ejecutivo, pues la heterogeneidad del poder Legislativo, incluidas posiciones nacionalistas o proteccionistas, pueden frenar el avance de los procesos de transnacionalización de las corporaciones multinacionales. Por ello, la democracia tiene que acotarse a los asuntos económicos domésticos del Estado nacional, ya que la integración política regional deforma los impulsos del "libre mercado", por pretender su regulación por parte de los poderes públicos.

Hay una interpretación digamos intermedia, que reconoce el carácter global y sistémico de la crisis, pero cuyo diagnóstico le hace pensar que mediante reformas profundas de la arquitectura financiera internacional y su correlato en los Estados nacionales, que hagan manejables las variables económicas de la crisis, ésta se puede superar. El optimismo por hacer de la crisis una oportunidad de superación, invade esta perspectiva. Propuestas como el Post-Consenso de Washington (Stiglitz, 2008) tienen, sin embargo, críticas muy atinadas respecto de la ortodoxia neoliberal, como son las relativas a las falacias de los programas de austeridad, la posición casi religiosa frente al control de la inflación y del salario, o la importancia del mercado interno para enfrentar la crisis global. No obstante, el énfasis sigue puesto en el polo tecnocrático de la coalición política del gobierno en turno, y no se concede poder alguno a los procesos 
de integración regional; el espacio para enfrentar la crisis se comparte entre un multilateralismo renovado de escala global, que democratiza primordialmente a las instituciones financieras internacionales, y a la escala de Estados nacionales con capacidad para emprender reformas de mercado, bajo mecanismos que mejoren los esquemas de gobernabilidad democrática nacional y local.

Un tercer enfoque, cuestiona el carácter pasajero o meramente económico de la crisis e insiste en que urgen distintos puntos de vista sobre su complejidad. Como lo señala Ugarteche (2013):

\begin{abstract}
La triple crisis es una entrada, donde las crisis energética, alimentaria y económica van de la mano. Otro enfoque es la crisis de larga duración [...] Otra es una crisis financiera que ya pasó (2007-2009) y entonces estamos a las puertas de otra crisis en Europa. Esta es una lectura muy anglosajona y metabolizada por la Organización para la Cooperación y el Desarrollo Económico (OCDE). Otras lecturas de más largo alcance permiten avizorar que se trata de un cambio de tiempos. En este sentido la postura de una crisis civilizatoria propuesta por Aníbal Quijano y Boaventura de Sousa Santos, está más cerca a la realidad observada que las anteriores más orientadas a que se trata de una crisis económica.
\end{abstract}

Si hablamos de una crisis civilizatoria, entonces los parámetros frente a la democracia cobran otra magnitud, ya que desde este enfoque se restituye un sentido sustantivo a la democracia al hacerla partícipe de aquellos asuntos que son de todas y todos. Si el modelo económico determina valores de civilización esquizofrénicos entre libertades y derechos, la nueva gramática democrática cuestionará el carácter supuestamente universal de esos (anti)valores, desde una resignificación de las condicionantes espacio temporales diversas que dan sentido a expresiones particulares de la democracia. Una gramática que se distancia del pensamiento único y que no se acota al Estado-nación, ni solamente al mundo de las instituciones, sino que lee con un sentido diacrónico y sincrónico, las transformaciones del poder y su manera de adecuarse al imaginario democrático. Por lo cual, esta nueva gramática transita de las coordenadas Norte-Sur, que dominan la integración comercial neoliberal, a las coordenadas Sur-Sur, de una integración autónoma que pretende "democratizar la democracia" (De Sousa Santos, 2003) en todas las escalas de su geografía política: global, supranacional regional, nacional y local. Desde esa lectura, la colonialidad del poder implica una crítica a los valores supuestamente democráticos sobre los que se erigió la civilización que está en crisis, los cuales fragmentan a las comunidades políticas, estigmatizan bajo el racismo y las excluyen del poder de decisión sobre los asuntos públicos (Martins, Paulo, 2012). 


\section{Democratizar la integración}

Solamente una interpretación de la crisis civilizatoria ofrece perspectivas promisorias para un escenario democrático que favorezca la integración autónoma de América Latina, pues ni la postura que entiende la crisis como pasajera, o como estrictamente comercial y financiera, o con posibles arreglos mediante reformas parciales, por más profundas que sean, ninguna de ellas van al fondo de la cuestión: la crisis capitalista en su expresión neoliberal con sus secuelas depredadoras, el incremento de la desigualdad, del racismo y la exclusión. Comprender el papel de la democracia en la integración necesita de una visión crítica sobre la teoría de la democracia, los paradigmas que están en debate y las exigencias para cada una de las escalas de actuación de comunidades políticas instituidas, en interacción con comunidades políticas instituyentes a través de los movimientos sociales. Para ello, será necesario abordar las consideraciones siguientes:

- La idea de democracia como eje global de referencia, y su vinculación con los acuerdos de cooperación y de la constitución de organismos internacionales, particularmente con la llamada gobernanza global;

- La configuración de nuevos instrumentos internacionales de protección del sistema de gobierno democrático, que se ha convertido en imperioso marco de unificación de los Estados;

- Las potencialidades de la democratización de los esquemas de integración regional en procura de derechos de ciudadanía, en un contexto internacional caracterizado por la fragmentación y multiplicación de actores de demandas y de necesidades;

ـ La desafección política, descrédito del sistema político y de partidos, el papel de los nuevos movimientos sociales como portadores de alternativas a la democracia "realmente existente".

La búsqueda de un imaginario democrático liberal occidental de carácter global, se expresa en el informe elaborado para la Comisión Trilateral en 1975, por el francés Michel Crozier, el estadounidense Samuel J. Huntington y el japonés Joji Watanuki, editado como The crisis of democracy (Crisis de la democracia: reporte sobre la democracia y la gobernabilidad, de la Comisión Trilateral, 1975). De acuerdo con Jorge Alonso (2013), ${ }^{1}$ prestigiado antropólogo mexicano,

los tres intelectuales diagnosticaron una situación cuasi caótica y explicaron que existían tres coordenadas que alteraban el orden en las naciones y consubstancialmente productoras de flujos disfuncionales en los sistemas democráticos.

1. Reflexiones inéditas, escritas a raíz del fallecimiento de Michel Crozier, el 28 de mayo de 2013. 
Un primer flujo lo denominaron "deslegitimización de la autoridad y la pérdida de confianza en el liderazgo" refiriéndose al Estado y partidos políticos de largo periodo en el poder, como consecuencia de la persecución de la igualdad y del individualismo, virtudes preciadas del credo democrático que porta el neoliberalismo, entendida la libertad como despliegue de capacidades de consumo y desapego de la comunidad.

El Informe de la Trilateral, desprecia el papel de las comunidades como tejido de sentimientos y tradiciones cuando en el núcleo comunitario la competencia está descartada como fin. Para Alonso (2013),

en un escenario donde todos son iguales y entre todos construyen el horizonte del futuro, la dinámica social es lenta y los cambios sociales también, porque el consenso, los acuerdos, las decisiones colectivas, el disenso incómodo y/o la imposición de las mayorías del centralismo democrático, no son funcionales para la sociedad que los neoconservadores querían implantar, de ahí que libertad de consumo, movilidad de pensar y de votar fue y siguió por muchos años verbalizándose hasta legitimarse dentro de las distintas comunidades que integran el mundo capitalista.

Un segundo flujo que registra el informe sobre la crisis de la democracia, se refiere a

la "sobrecarga" que tiene el Estado para gobernar, custodiar la seguridad, emitir leyes, administrar los fondos y empresas estratégicas, los recursos públicos e incluso los territorios y espacialidades marítimas y cultural.

El tercer flujo señalado en el Informe, consiste

en la fragmentación de los partidos políticos y una suerte de pérdida de identidad de los mismos, de ahí que cada país debería iniciar una reforma en lo concerniente a leyes electorales, desincorporadas del Estado, pero asistidas por los medios de comunicación con competencias electorales abreviadas, todo ello posibilitaba que en las oquedades de las nuevas reformas electorales pudiesen entrar presiones políticas de sectores ligados al mercado o negocios, medios de comunicación e incluso gobiernos ajenos.

Desde una visión de superioridad anglo-euro-céntrica, esta concepción autorizada de la democracia, acotada a su aspecto electoral, que delega decisiones en representantes, se asocia de manera indisociable con el concepto de gobernanza, que enfatiza la eficiencia y la legalidad por encima de la legitimidad. Ugarteche (2013), nos recuerda que 
la gobernanza global antes centrada alrededor del FMI, el Banco Mundial y el multilateralismo público, organizado por los Estados Unidos tras la segunda guerra, ha perdido fuerza. La crisis desde el 2008 ha mostrado que los Estados no sirven para gran cosa salvo trasladar recursos al Mercado financiero, y que solo el G20 es la solución.

El Informe de la Trilateral fue el punto de partida para la elaboración del pensamiento único sobre el que se funda la globalización neoliberal, el cual influye sobre el imaginario democrático de Estados nacionales y de formatos políticos supranacionales relacionados con la integración. Sea como condicionante para el establecimiento de relaciones internacionales, sea como argumento para calificar a los regímenes que no se apegan a sus valores, la democracia es objeto de disputa. En los organismos internacionales de concertación político-diplomática, es cada vez más citada la forma democrática de gobierno como una condición que se antepone para la igualdad de trato enmarcado en el Estado de derecho. Como lo plantea Naranjo (2013):

El primer paso en la fijación de dichos derroteros básicos de respeto Universal constituyó la declaración Universal de Derechos Humanos 1948, que dio relevancia a la inclusión de la democracia como el régimen condicional del nuevo escenario internacional.

Los destinatarios de este imaginario son en primera instancia los Estados nacionales, pero crecen en importancia las instituciones supranacionales regionales y particularmente los esquemas de integración. De acuerdo con Naranjo (2013):

la Declaración de la Cumbre del Milenio de las Naciones Unidas en 2000, donde bajo la égida de la promoción de la democracia y el fortalecimiento del imperio del derecho. (n. V), como uno de sus objetivos, reitera la necesidad de la existencia de regímenes democráticos para garantía de los valores y principios de las relaciones Internacionales: Libertad, igualdad, solidaridad, tolerancia, respeto a la naturaleza y responsabilidad común (n. I.6).

Aunque supuestamente inspirada en valores democráticos, La Organización de Estados Americanos (OEA, 1948), se fue desacreditando por su inoperancia ante los regímenes militares de facto que marcan un oscuro pasado en Latinoamérica, durante los 70 y los 80. Un periodo de transición democrática estudiado por Guillermo O’Donnell, Philippe Schmitter y Laurence Whitehead (1986) cuyo análisis es una referencia paradigmática en torno al paso de gobiernos militares a gobiernos civiles en Latinoamérica. Aunque la matriz estado-céntrica domina estudios y acciones políticas alrededor de la democratización, será en septiembre de 2001 que surge una idea panamericana de imaginario democrático, pues a iniciativa de Estados Unidos se propondrá la Carta Democrática Interamericana ("Régimen internacional en defensa de la democracia"); 
antes, ya el Acuerdo Global, México-Unión Europea (2000) propuso una Cláusula Democrática, condición que acompaña todos los tratados de libre comercio que la UE tiene con diversos países latinoamericanos.

\section{La democracia en los esquemas de integración}

Andrea Naranjo (2013), hace un recuento sobre la incorporación de los valores democráticos y sociales en cada uno de los esquemas de integración:

La Comunidad Andina de Naciones, pionera con la suscripción del Manifiesto de Cartagena de Indias, suscrito en el marco de la cumbre de jefes de Estado celebrada de 1989, hace una descripción que permitiría la inclusión definitiva de la dimensión social dentro del Esquema Andino. Ya el protocolo modificatorio de Trujillo explicita la democracia, dentro del andamiaje político-institucional del sistema Andino de Integración (SAI), que ya contaba con el Parlamento Andino, desde 1979 y se inscribía en la Carta Social Andina de 1994 como derrotero de la integración junto con los derechos humanos, al reafirmar el compromiso con la promoción, el fortalecimiento y el perfeccionamiento del sistema democrático, erigido sobre bases de equidad y solidaridad.

Naranjo (2013), destaca que

La Carta social [Andina], además, establece un amplio catálogo de derechos económicos sociales y culturales, e incluye a todos los sectores sociales, jóvenes, mujeres, pueblos indígenas y comunidades afro descendientes y raizales.

Siguiendo a Naranjo (2013):

Aunque la Carta Social Andina, ha sido objeto de varias modificaciones, constituye en instrumento central de política social de tendencia democrática, extensivo a la sociedad civil, con la Carta Andina para la Promoción y Protección de los Derechos Humanos. [...] Mercosur, fue más explícito al incluir dentro del Acuerdo de Madrid de 1995, la democracia como fundamento de la cooperación, y en el marco de la cumbre presidencial de 1996, insertó una cláusula democrática, como condición esencial para la cooperación, susceptible de ser aplicada ante 'toda alteración, del orden democrático', el cual se erigía como un obstáculo insalvable para la continuidad del proceso de integración.

Por su parte, el Protocolo de Ushuaia sobre Compromiso Democrático y la Declaración Política del Mercosur, revalidados en la Carta de Buenos Aires sobre Compromiso Social en El Mercosur, Bolivia y Chile de 2000, acordó crear el observatorio de la Democracia del Mercosur (ODM), para dar seguimiento a procesos electorales y realizar 
actividades relacionadas, con la consolidación democrática en la región, instancia que ha jugado un rol estratégico ante los procesos electorales recientes.

En su momento, establece Naranjo, el sistema de Integración de Centroamérica (SICA), [...] ha incorporado, dos regulaciones que sobresalen por su carácter vinculante: La primera de ellas, el Tratado de integración social Centroamericana, de 1995, que permite, desarrollar la dimensión social erigida sobre principios de solidaridad, no discriminación y respeto al medio ambiente, como pasos necesarios para la estabilidad democrática, derivados del Protocolo de Tegucigalpa. Ese mismo año, se suscribe el Tratado Marco de Seguridad democrática, en San Pedro Sula, catalogado como un marco normativo e institucional que destaca aspectos sociales, integra a la sociedad civil como partícipe activo del proceso e incluye un nuevo concepto de democracia.

Además, Naranjo registra los documentos que respaldan la Alianza Centroamericana para el Desarrollo Sostenible ALIDES, que incluye la democracia como un aspecto de política social integral.

En lo que respecta a la Unión de Naciones Sudamericanas Unasur, se pretendió reforzar la coordinación política entre la CAN, el Mercosur y la Asociación Latinoamericana de Integración Aladi. El Tratado de Brasilia, en 2008, reitera los objetivos de construcción participativa y consensuada, en procura del fortalecimiento democrático, criterios trazados desde las reuniones de jefes de Estado de Ecuador 2002 y de Brasilia 2000. Será en la III Reunión Ordinaria del Consejo de Jefas y Jefes de Estado y de Gobierno de la Unión de Naciones Suramericanas, celebrada en Quito Ecuador, en 2009, que se reafirmará el "compromiso con la democracia, como único sistema para resolver los desafíos y brindar mayores esperanzas y oportunidades a nuestros pueblos, con pleno respeto a los Derechos Humanos y a las libertades fundamentales" agregando la prohibición de reconocimiento de un gobierno ante "la ruptura del orden institucional democrático". ${ }^{2}$

La Comunidad de Estados latinoamericanos y del Caribe, creada en 2010, también incorpora a la democracia como base de configuración de un nuevo organismo intergubernamental, como lo plantea en su declaración fundacional:

la democracia (como) un valor universal que hace parte del acervo histórico del Grupo de Río (G Río) y de la Cumbre de América Latina y el Caribe sobre Integración y Desarrollo (CALC), incorporando la Cláusula de compromiso con la promoción, defensa y protección del Estado de Derecho, del orden democrático, de la soberanía de los pueblos, de los Derechos Humanos y las libertades fundamentales. ${ }^{3}$
2. Citada por Naranjo (2013): III Reunión Ordinaria del Consejo de Jefas y Jefes de Estado y de Gobierno de la Unión de Naciones Suramericanas. Declaración Presidencial de Quito. Quito, Ecuador, 2009

3. Comunidad de Estados Latinoamericanos Y Caribeños (Celac) (2011). Declaración Especial sobre la Defensa de la Democracia y el Orden Constitucional, 3 de diciembre de 2011 . 
4. Desde 1994 se hace la declaración fundadora de la Cumbre: "preservar y fortalecer, la comunidad de democracias de las Américas, Promover la prosperidad a través de la integración económica y el libre comercio Erradicar la pobreza y la discriminación, Garantizar el desarrollo sostenible y conservar nuestro medio ambiente".
La Celac representa un parteagüas en la historia latinoamericana, pues por primera vez se reunieron Jefes de Estado y de Gobierno, sin la tutela de potencia extranjera alguna. Su autonomía reclama un nuevo espacio, particularmente frente a las relaciones interamericanas protagonizadas por Estados Unidos, y las reuniones intergubernamentales de todos los gobiernos del continente que propiciara para impulsar el tripie democracia, reformas de mercado, seguridad hemisférica. En el marco de la Primera Cumbre de las Américas, celebrada en Diciembre de 1994, se concierta, el Pacto para el Desarrollo y la Prosperidad: Democracia, Libre Comercio y DesarroIlo Sostenible en las Américas, ${ }^{4}$ aunque después de la VI Cumbre de las Américas (Preciado, 2013) no parecen tener viabilidad futura estas cumbres, dado el fracaso del ALCA que promovía intensivamente Estados Unidos y en particular la creación de la Celac, como ente de integración autónomo de la región, que se opone al bloqueo estadounidense contra Cuba, la intromisión de Washington al apoyar golpes de Estado en Honduras y Paraguay, así como contra la complicidad del Departamento de Estado a favor del Reino Unido en el asunto de la soberanía argentina sobre las Malvinas.

\section{Paradigmas democráticos en debate}

El debate teórico y la sociología política sobre la universalidad de los valores democráticos, sus contenidos sustantivos e incluso los adjetivos que la conforman, permiten trazar una gramática que está en debate. Ya ubicamos cómo surge un imaginario con pretensiones globales desde el pensamiento único. La "democratización liberal y de mercado", parecía convertirse en una de las condiciones para amortiguar la crisis global y sistémica por la que atraviesa América Latina, región que registra en su memoria histórica traumáticos procesos de autoritarismo en sus sistemas políticos.

La democracia procedimental se impulsó a lo largo y ancho del subcontinente y, los sistemas multipartidistas, limitados a la figura de la representación, parecieron convertirse en el antídoto contra el autoritarismo y la fuente de un desarrollo prominente para el futuro, que situó en su centro de interés los procesos de integración latinoamericana. Mientras tanto, el mismo discurso neoliberal que enaltecía las ventajas del libre mercado, la desregulación, las privatizaciones y el Estado mínimo, de acuerdo con los lineamientos del Consenso de Washington, estableció este modelo ideológico para la conducción de la integración, y le dio carácter condicionante para la estabilidad y la gobernanza.

Sin embargo, falla la conciliación entre el conflictivo triángulo Estado-Sociedad-Mercado, que presuponía dicha "consolidación" de la democracia liberal-procedimental en la región, y el apego incondicional al modelo de integración neoliberal, fue el primer gran indicio de que la imposición de un modelo de organización política y un 
sistema de valores homogéneo, promovido como democracia liberal, representaba fundamentalmente, un discurso dominante y una hegemonía socio-cultural de occidente sobre las prácticas políticas de los actores latinoamericanos.

Ante la desigualdad y la exclusión producto de ese modelo, emergieron un conjunto de interrogantes orientadas a redibujar los esquemas democráticos en la pizarra latinoamericana, y el modelo de integración que los Estados deberían seguir. Así, surgieron proyectos políticos con una nueva gramática democrática de resistencia y reconocimiento de las necesidades relacionadas con la integración autónoma latinoamericana. Frente a la democracia elitista, "de pocos para pocos", fundada sobre una coalición política tecnocrática, acotada a los procedimientos electorales, la delegación de decisiones en representantes y la subordinación frente a las reformas de mercado que impulsa el Estado Corporación, surge un imaginario transformador de los contenidos y alcances que nutren a la democracia.

La democracia participativa, cuyas características esenciales se orientan hacia una dimensión multitemática, que va de los mundos de vida, al rol activo de las comunidades, que se orienta al ataque del problema de la desigualdad social y por lo tanto que demanda derechos para cuestionar el modelo económico, tanto como las políticas sociales y culturales que no favorezcan la vida democrática.

Una democracia participativa multi-escalas, que se propone actuar a lo largo y ancho de la geografía política: lo global, lo supranacional regional - y por lo tanto sobre los procesos de integración latinoamericana -, lo nacional y lo local, desde parámetros críticos de la colonialidad del poder y de la crisis civilizatoria. Prácticas que demandan visibilizar a los actores sociales ausentes, como lo propone Boaventura de Sousa (2006) en su "Sociología de las ausencias y de las emergencias". Alrededor de lo cual se construye una referencia paradigmática (Arrighi, citado por Reifer, 2009): el Sur Global.

Una democracia participativa de tres pisos, siguiendo a de Sousa (2009) y a Avritzer (2010) 1) representación de calidad, con supervisión eficaz de las y los representantes; 2) participación directa en todos los ámbitos de lo público; 3) la democracia comunitaria, que se identifica con actores colectivos provenientes de etnias y pueblos originarios, que enriquecen desde la diversidad intercultural los derechos de ciudadanía.

En el intersticio de los dos paradigmas en disputa, el neoinstitucionalista, inspirado en el Rational y el Public Choice (De la Garza, 2005) y el paradigma crítico, que acude a la teoría de la complejidad del Estado social, así como a la crítica de la colonialidad del poder, se encuentra un ámbito de debate unificador: la calidad de la democracia. Más allá de los índices que miden el grado de democracia de los regímenes estatales, o de 
la medición de la gobernanza, supuestamente de carácter democrático, se trata de comprender esos ámbitos múltiples planteados antes (Morlino, 2012): ¿qué calidad ofrece la democracia para el combate de la desigualdad? ¿qué ofrece ese régimen para el fortalecimiento de los derechos humanos? ¿cuál es la capacidad de diálogo y escucha de los actores ausentes/excluidos?

Pero también cabe preguntarse ¿qué aportan los estudios sobre calidad de la democracia para un nuevo paradigma? De acuerdo con Morlino (2012, pág. 9),

\begin{abstract}
la calidad de una democracia puede ser evaluada observando sus diversas dimensiones. En este artículo se argumenta que las dimensiones más importantes tales como Estado de Derecho, Rendición de Cuentas Electoral, Rendición de Cuentas Interinstitucional, la Participación ciudadana y la Competencia entre partidos están estrechamente interrelacionadas.
\end{abstract}

5. The rule of Law, Accountability y Responsiveness, son los conceptos básicos para el estudio de la calidad de la democracia.
Un conjunto de procedimientos que deben de ser tomados en cuenta por el nuevo paradigma democrático. ${ }^{5}$

\section{Integraciones neoliberales, postneoliberales y contrahegemónicas}

La preponderancia estadounidense en las relaciones interamericanas, cuestionada por la enérgica postura adoptada por los países latinoamericanos miembros de la Celac en la Cumbre de las Américas de Cartagena en 2012, está disminuyendo gracias al fortalecimiento del proceso de emancipación frente a las políticas neoliberales que vienen implementando algunos países, principalmente de Suramérica, así como las resistencias sociales organizadas que contra ese modelo surgen en toda la región. No obstante, la ofensiva de las relaciones hegemónicas interamericanas desde Estados Unidos, aunadas a las presiones comerciales y financieras de la Unión Europea y de distintos países del Pacífico asiático, plantean severos obstáculos frente a las tendencias autónomas latinoamericanas. En nuestra región, destacan las alianzas que opera la diplomacia comercial, el Departamento de Estado y la doctrina de seguridad estadounidense. La agenda que resulta de todo ello, se podría caracterizar bajo cuatro rasgos:

1. Una gama creciente de países en los que se instauran tratados de comercio de los Ilamados multi-bilaterales, como es el caso del Cafta+RD, relanzan la vieja idea de una integración continental americana (neo-panamericanista), comandada por la potencia del Norte.

2. Se retoman las llamadas reformas estructurales de mercado, como 
parte sustantiva de las relaciones interamericanas que comanda Estados Unidos, las cuales refuerzan simultáneamente privatizaciones, liberalizaciones y proyectos de flexibilidad laboral, al mismo tiempo que desde el entorno internacional se profundiza la re-primarización de la economía y se acentúa el modelo neo-extractivista.

3. Se proyectan nuevos lazos geopolíticos desde la perspectiva transpacífica, dado el creciente protagonismo de China y del relanzamiento de los espacios de integración comercial del Pacífico asiático.

4. Diversos movimientos sociales como las Cumbres de los Pueblos, o la Articulación de los Movimientos Sociales hacia la Alba, lanzan persistentes críticas y condenas sobre las limitaciones del carácter cupular y elitista que representa los tratados y acuerdos comerciales de inspiración (neo)panamericanista, que convoca el gobierno estadounidense, y el carácter neoliberal que impulsa a la integración con la Unión Europea, o con diferentes países del Pacífico Asiático.

Respecto al primer punto, no se puede ignorar que los tratados económicos que se han venido instaurando en la región latinoamericana muestran la tendencia de volverse contraproducentes a la larga. De hecho, las propuestas de Estados Unidos giran en torno a un tripié formado por la implementación de Tratados de Libre Comercio (TLC's), por el ofrecimiento de imaginarios democráticos condicionados al establecimiento de reformas de mercado y por la extensión del concepto estadounidense de seguridad nacional en diversas áreas de acción geoestratégica: la Iniciativa Mérida, el Proyecto Mesoamericano, que vino a actualizar al Plan Puebla Panamá, el Plan Colombia y la Iniciativa Andina.

En cuanto al segundo punto, si bien desde el sur de América Latina se trabaja en su proceso de independencia, tanto de manera económica como política con respecto a América del Norte, hay un retorno de gobiernos proclives a las reformas de mercado neoliberales; Chile, con el gobierno de Sebastián Piñera (2010-2014); Panamá, con el gobierno de Ricardo Martinelli (2009-2014); Perú, con la presidencia de Ollanta Humala (2011-2016), que ha retrocedido en sus propósitos de oponerse a las reformas de mercado. Además, en Colombia, Costa Rica, Guatemala, se refrendaron gobiernos que también abrazan los postulados de reformas neoiberales. Países a los que se añadieron golpes de Estado que pretenden abiertamente instaurar privilegios para la economía de mercado, como son los casos de Honduras y de Paraguay.

El papel de los países que integran América Latina con propuestas de corte "postneoliberal" (Sader 2013), dentro de la economía mundial capitalista, Argentina, Bolivia, 
Brasil, Ecuador, Uruguay y Venezuela, se proyecta hacia la construcción de instancias integradoras supranacionales como la Unasur, el Mercosur, o la Alternativa Bolivariana para los Países de Nuestra América (Alba). Esta última se proyecta con miras contrahegemónicas. En el resto de países prevalecen las políticas económicas de encausamiento de los TLC's con Estados Unidos y la aplicación más o menos incondicional de los principios del Consenso de Washington, que impulsan la privatización, la liberalización comercial y financiera mediante desregulación económica, y la flexibilidad laboral, como motor de la competitividad y la productividad orientadas fundamentalmente a la exportación hacia el mercado mundial.

Tercer aspecto, el espacio transpacífico, representa un ámbito que está sujeto a tendencias contradictorias. Desde el proyecto de integración latinoamericana autónoma, los BRICS tienden a formar un contrapeso al grupo de los países centrales, mientras que simultáneamente, hay proyectos de integración decididamente neoliberales que acercan a los principales países de la región que se insertan en la Cuenca del Pacífico, con las políticas comerciales de Estados Unidos y Canadá, hacia el prominente espacio económico en el que destaca China. La llamada Alianza del Pacífico, es una nueva entidad, que agrupa a México, Perú, Colombia y Chile, e incorpora como observadores a Costa Rica y Panamá. De acuerdo con Alpízar (2012) , esta Alianza

fue creada para alcanzar "el libre flujo de bienes, servicios, capitales y personas, a fin de situar a esos países en mejores condiciones para el acercamiento y consolidación de las relaciones económicas y comerciales con la dinámica región asiática".

En cualquiera de los casos, trátese de la integración neoliberal, o de las vertientes post-neoliberales pragmáticas o contrahegemónicas, la crisis global del capitalismo es acentuada por lo que podría llamarse una re-materialización de la base de acumulación, la cual está conduciendo hacia un modelo neo-extractivista que somete crudamente a los procesos de integración hacia conflictos de gobernabilidad intensos. Tanto en los países donde predomina la ortodoxia neoliberal, como en aquellos donde se buscan alternativas, los problemas relativos a ese neo-desarrollismo, provocan conflictos sociales, ambientales y políticos que incrementan la desigualdad social, disminuyen los márgenes de soberanía en el manejo de los recursos primarios y tensionan la relación entre gobernantes y gobernados, por la imposibilidad de atender las demandas de la población, principalmente originaria y afrodescendiente, frente a lo que David Harvey (2004) Ilama la acumulación por desposesión, y que Maristella Svampa (2010) caracteriza como el giro eco-territorial, depredador y desorganizador del tejido social. 


\section{Imaginario latinoamericano, democratización y movimientos sociales}

La nueva gramática democrática que experimentan países y regiones diversas de Latinoamérica, está vinculada con los procesos de integración y los imaginarios asociados con el sentido y la direccionalidad que toman las diferentes versiones integradoras: el (neo)panamericanismo; el surlatinoamericanismo, dado el avance integrador en Suramérica; y el latinoamericanismo, imaginario que persiste en la memoria y las prácticas estatales y colectivas como aspiración de unidad y de convergencia (Ver Cuadro 1).

Este conjunto es atravesado por formas de poder específicas, relativas a la política internacional, en el marco de tensiones entre unilateralismo y bilateralismo. Mientras que la diplomacia latinoamericana ha logrado constituir espacios de diálogo y concertación de carácter multilateral, primero con el Grupo de Río y todos sus antecedentes, la política exterior estadounidense, eminentemente unilateral, construye su hegemonía sobre la base de las hasta ahora seis Cumbres de las Américas, las cuales reúnen a todos los mandatarios-as del continente, con excepción de Cuba. A pesar del cambio que trajo consigo la administración Obama, respecto a su antecesor George W. Bush, particularmente en la reorientación de la política exterior inspirada por la combinación de poderes suaves, duros, inteligentes (soft-hard-smart power), no se registran avances en la democratización de las relaciones internacionales que puedan impactar sobre los esquemas de integración. Contrariamente, el sistema hegemónico interamericano es doblemente cuestionado: ni las Cumbres de las Américas tienen futuro, si no se incorpora Cuba en ese proceso; ni se aceptan mas medidas unilaterales estadounidenses, pues la creación de la Celac, da nuevos aires a la autonomía latinoamericana.

Hay formas de poder geoestratégicas y geopolíticas que encuadran las relaciones centro-semiperiferia-periferia en el sistema mundo. América Latina tiene una amarga experiencia en lo que se refiere a su soberanía, independencia y autonomía nacional y regional. Mediante doctrinas de seguridad, plasmadas en planes geoestratégicos, la política imperial de la potencia del norte impone su doctrina de seguridad nacional al continente americano; impone su visión (neo)panamericanista antiterrorista y sus estrategias para combatir al crimen organizado, de manera unilateral. Expresión de ello son los planes geoestratégicos que cubren su tercera frontera: México, Centroamérica y el Caribe, mediante planes cada vez más articulados entre sí y paralelamente refuerza la militarización del conjunto continental: los Comandos Norte y Sur; el relanzamiento de la IV Flota; la ampliación y sofisticación de sus bases militares. Asimismo, planes como la Alianza para la Seguridad y la Prosperidad de América del Norte, la Iniciativa Mérida, el Proyecto Mesoamericano (antes Plan Puebla Panamá), el Plan Colombia y la Iniciativa Andina, implican alianzas con actores nacionales que impulsan 
6. Cf. Tratado de la Unasur: "Artículo 17 Parlamento. La conformación de un Parlamento Suramericano con sede en la ciudad de Cochabamba, Bolivia, será materia de un Protocolo Adicional al presente Tratado. Artículo Transitorio Las Partes acuerdan designar una Comisión Especial, que será coordinada por el Consejo de Delegadas y Delegados y estará integrada por representantes de los Parlamentos Nacionales,

Subregionales y Regionales con el objetivo de elaborar un Proyecto de Protocolo Adicional que será considerado en la IV Cumbre de Jefas y Jefes de Estado y de Gobierno. Esta Comisión sesionará en la ciudad de Cochabamba. Dicho Protocolo Adicional establecerá la composición, atribuciones y funcionamiento del Parlamento Suramericano." Evo Morales, comprometió $\$ 64$ millones de dólares, para la construcción del Parlamento de Unasur en Cochabamba, Bolivia, Diario Hoy (20/06/2013), disponible en: <http:// www.hoy.com.ec/ noticias-ecuador/ bolivia-dispone-de64-millones-parasede-de-parlamentode-unasur-584078. html>. una integración securitaria que acompaña y condiciona la entrada a sus proyectos de integración comercial.

Otro foco de conflictos geopolíticos y geoestratégicos entre los imaginarios de la integración y la democracia, se refiere a la operación del modelo de desarrollo en sus bases materiales: energéticas, alimentarias, lucha por la biodiversidad y movimientos-desplazamientos de población, lo cual produce conflictos que limitan la integración autónoma latinoamericana. Nuestra región se enfrenta dividida ante tales megatendencias geopolíticas, pero hay ciertos avances, aunque parciales, en la concreción del imaginario latinoamericanista: la Iniciativa para la Integración Regional Suramericana (IIRSA), la integración petrolera entrañada en la Alba, con Petroamérica, Petrosur, Petrocaribe y las alianzas entre algunas empresas petroleras, como las de Venezuela, Ecuador, Bolivia y Argentina. Sin embargo, como se verá después, el imaginario latinoamericanista muestra contradicciones internas, pues el empuje de estrategias neodesarrollistas desde algunos gobiernos amplía la brecha entre las políticas de desarrollo y los actores sociales de base popular.

Con el regreso de los enfoques estado-céntricos, se acrecienta el debate sobre el poder de los Estados nacionales para vincular democracia e integración. Así, la constitución del régimen político, de las instituciones jurídico-políticas nacionales y supranacionales, ante el avance de procesos integradores, repercute en la transformación de los poderes republicanos: Ejecutivo, Legislativo y Judicial. Si el pensamiento único del imaginario (neo)panamericanista se propone implantar un modelo democrático liberal de mercado, como condición para participar dentro del proceso de integración comercial neoliberal, desde el imaginario latinoamericanista se procesan otras iniciativas que exploran nuevos formatos participativos y democráticos nacionales, comunitarios que además, en el caso sudamericano, constituyen nuevas instancias democráticas supranacionales, que incluyen el Consejo de Defensa Suramericano. Sin embargo, hay una sobreposición entre Parlamentos supranacionales y subregionales que no responden a las demandas de calidad de la representación y de impulso a la democracia participativa. Las diferencias entre Parlamento Andino, o el Centroamericano y el del Mercosur o el de la Amazonía, son abismales en cuanto a su representatividad y formatos de consulta popular. Se espera que el Parlamento de la Unasur provoque nuevas sinergias políticas y ciudadanas. ${ }^{6}$ En la escala latinoamericana, La débil institucionalidad del Parlatino, plantea un desafío para que la Celac pueda lograr la densidad e intensidad requeridas por una integración comunitaria supranacional democrática.

Contrapoder y subalternidad constituyen ejes fundamentales sobre el debate democrático en torno de la integración. Ampliamente estudiados en las ciencias sociales latinoamericanas, la tensión entre procesos instituyentes e instituidos que detonan los movimientos sociales es clave para comprender los conflictos por los que atraviesa 
la democratización (Gohn y Bringel, eds., 2013). La amplia gama de demandas que plantean al sistema político y social, aunada a cuestionamientos alrededor de la vida social vinculada con los mundos de vida cotidiana que crean, no siempre pueden ser procesadas en el gobierno, la instauración de derechos y la creación de ciudadanía. Si bien varios procesos democratizadores en Suramérica desembocaron en tiempos recientes en Constituyentes pacíficas - o en reformas constitucionales de amplio calado, como Brasil en 1988 -, fundadoras de un nuevo pacto social que incluyó varias aspiraciones planteadas por la acción social colectiva, hay nuevas tensiones introducidas por el anti-modelo de desarrollo y su creciente influencia aún en aquellos casos donde se experimentan nuevos regímenes políticos que han plasmado en sus instituciones aspiraciones democráticas.

Desde el enfoque (neo)panamericanista, sus referencias son la democracia elitista y mercantilizada; por su falta de escucha y permeabilidad frente a las acciones colectivas, esas democracias están secuestradas por el utilitarismo a ultranza, la débil capacidad de regulación estatal de lo social y el refuerzo de la dominación. Estamos ante el Estado-centauro (Wacqant, 2012, pág. 505)7 , o el Estado Policial, que criminaliza toda aquella acción colectiva que cuestione el orden realmente existente. En las experiencias post-neoliberales, el imaginario latinoamericanista ha logrado reivindicaciones públicas en el campo sociopolítico institucional estatal, sin embargo, en la relación entre integración y democracia permanecen y se amplían ciertas tensiones entre la agenda social, la agenda de gobierno y las dinámicas del mercado mundial que marcan el ritmo de acumulación capitalista.

Tanto en donde existe una institucionalidad supranacional regional, como en los países apegados a la ortodoxia del libre comercio, surgen distintas redes de resistencia que además van prefigurando alternativas. El imaginario latinoamericano propicia una suerte de laboratorio de innovación social desde la alteridad y desde escalas socioespaciales que vinculan lo local con lo global: el Foro Social Mundial, o Vía Campesina; pasando por las mediaciones nacionales: agrupaciones opuestas a los acuerdos de libre comercio; supranacionales: Foro Mesoamericano de los Pueblos; incluso en la escala americana: la Alianza Social Continental. Los imaginarios latinoamericanista y del Sur Global se acercan en su crítica al poder con un amplio repertorio emancipador, cuyas prácticas desbordan la lectura democrática en clave estatal. Latinoamérica es una región donde los imaginarios democráticos se leen en plural, pues coexisten compromisos con la institucionalidad, como lo muestra el Alba de los Movimientos Sociales, ${ }^{8}$ a la par de vastos movimientos que se oponen al giro eco-territorial del modelo neo-extractivista, que además cuestionan la vacuidad de las democracias realmente existentes y por lo tanto la participación electoral y en gobiernos limitados en su accionar por el Estado Corporativo mundial. Tensiones y conflictos que se abordan en las conclusiones.
7. Wacqant plantea "o conceito de Bourdieu de 'campo burocrático', para propor uma via média entre essas duas abordagens, que concebe $o$ neoliberalismo como uma articulação entre Estado, mercado e cidadania, aparelhando o primeiro para impor a marca do segundo à terceira. Essa concepção repatria a penalidade para o centro da produção de um Estadocentauro, que pratica o laissezfaire no topo da estrutura de classes e o paternalismo punitivo na base."

8. "La Articulación de Movimientos Sociales hacia el Alba es una propuesta de integración continental antiimperialista, antineoliberal y antipatriarcal, impulsada por movimientos de base social organizada y con capacidad de movilización popular, que luchan por la igualdad, la libertad y una auténtica emancipación de la región.", disponible en: <http://www. albamovimientos. org/¿que-es/ 24> 
CUADRO 1

IMAGINARIOS Y FORMAS DE PODER EN DISPUTA

\begin{tabular}{|c|c|c|c|}
\hline $\begin{array}{l}\text { Imaginario / } \\
\text { forma de poder }\end{array}$ & $\begin{array}{c}\text { Neo-Panamerica- } \\
\text { nismo }\end{array}$ & $\begin{array}{l}\text { (Sur) Latino- } \\
\text { americanismo }\end{array}$ & Latino-americanismo \\
\hline $\begin{array}{l}\text { Unilateralismo- } \\
\text { bilateralismo }\end{array}$ & $\begin{array}{l}\text { Hegemonía cumbre } \\
\text { de las Américas }\end{array}$ & Autonomía & Autonomía (discursiva) \\
\hline $\begin{array}{l}\text { Geoestrategia y } \\
\text { geopolítica }\end{array}$ & $\begin{array}{c}\text { Aspan + iniciativa mérida } \\
+ \text { proyecto mesoameri- } \\
\text { cano + plan colombia + } \\
\text { iniciativa andina }\end{array}$ & $\begin{array}{c}\text { lirsa + consejo de } \\
\text { defensa sur-americano }\end{array}$ & $\begin{array}{l}\text { Concertación y } \\
\text { cooperación }\end{array}$ \\
\hline Régimen político & $\begin{array}{c}\text { Estado nacional + } \\
\text { democracia liberal + } \\
\text { carta democrática OEA }\end{array}$ & $\begin{array}{l}\text { Supra-nacional + } \\
\text { parlamentos } \\
\text { sub-regionales }\end{array}$ & $\begin{array}{l}\text { Supra-nacionalidad } \\
\text { débil (Parlatino) }\end{array}$ \\
\hline Movimientos sociales & Criminalización & $\begin{array}{c}\text { Redes de resistencia } \\
\text { y alternativas }\end{array}$ & $\begin{array}{l}\text { Multiescalas: local-global } \\
\text { americano sur global }\end{array}$ \\
\hline
\end{tabular}

\section{Cuatro desafíos de}

la nueva gramática democrática en la integración

\section{Reforma del Estado vs. Reformas de mercado}

En los procesos de integración, la clave es de carácter interestatal. Sin embargo, la reforma del espacio público por excelencia que es el Estado, se encuentra aprisionada por las reformas de mercado que propician y acuerdan las instituciones internacionales orientadas a mantener la estabilidad macroeconómica a toda costa. Frente a esas tendencias hegemónicas de la ortodoxia neoliberal surge una nueva gramática democrática en la que destacan:

- Reforma Constitucional de amplio calado, como el caso de Brasil y Colombia; Constituyentes pacíficas, como Bolivia, Ecuador y Venezuela, que cuentan con nuevos instrumentos para moderar y modular la inserción de sus respectivos países en el proceso de integración. Ámbitos desde los cuales estos países caracterizados provisoriamente como post-neoliberales han logrado mayor autonomía frente a los procesos de integración dominantes.

ـ Estado Plurinacional, que reconoce la diversidad étnica y que propicia una transformación del programa de la modernidad fundador del Estado nacional etnocéntrico en nuevos formatos de ciudadanía y participación en los asuntos públicos. Aunque no terminan los conflictos entre integración supranacional e integración comunitaria de los pueblos raizales, están surgiendo nuevos imaginarios de comunidad políti- 
ca desde las organizaciones de base étnica, así como desde los Estados plurinacionales mismos, para oponerse a una integración comercial que los desintegra.

- Inter-culturalidad, desde un enfoque de alteridad abierto a otras y otros, que reivindica el derecho a la diferencia, como derechos humanos de tercera generación, lo cual combina la nueva estatalidad con la globalización de derechos asociados con la democracia, como la Corte Penal Internacional, o la Organización Internacional del Trabajo. A pesar de nuevas leyes que buscan evitar cualquier forma de racismo o de discriminación, la integración regional supranacional plantea temas irresolubles que se desprenden del impacto de la acumulación capitalista, que fragmenta y disgrega los territorios y las culturas de los pueblos originarios.

2. Debate sobre el desarrollo y la democracia En el PNUD (2004), se destaca:

1) la desigualdad y la pobreza son las principales deficiencias sobre el avance de la democracia como régimen político en América Latina;

2) el desarrollo de la democracia depende de que se amplíe de manera decidida la ciudadanía social, sobre todo a partir de la lucha contra la pobreza y desigualdad, y de la creación de empleo de buena calidad y;

3) con Estados débiles y mínimos solo puede aspirarse a conservar democracias electorales.

La democracia de ciudadanas y ciudadanos requiere de una estatalidad que asegure la universalidad de los derechos. La democracia de calidad está jalonada por una nueva gramática que si bien no corresponde estrictamente a la integración regional supranacional, si modela el contexto en que ésta se desenvuelve:

- Bienestar subjetivo que acompañe al bienestar objetivo. Nuevas formas de medición del "progreso" se imponen en las cuentas nacionales, lo cual redunda en nuevas concepciones sobre el desarrollo. ¿Qué tanto aporta la integración al bienestar? Es una pregunta que nutre la integración regional, pues los parámetros del desarrollo no se sincronizan con las políticas públicas, ni con las agendas sociales demandadas por el impacto negativo del crecimiento económico. 
๑ Estado del Buen Vivir, en su versión quechua, aymara o maya, significa quizá el aporte central a la nueva gramática democrática que experimentan algunos países y regiones de América Latina. Su integralidad y cosmovisión holista de comunidad y naturaleza pone, sin embargo, en entredicho los presupuesto fundamentales de la integración tanto en su versión ortodoxa neoliberal como post-neoliberal.

- Biopolítica-biopoder, son términos que modifican los dispositivos de la persona, la escala del cuerpo, sus sentimientos y emociones. Desde Latinoamérica se aportan consideraciones estratégicas que están cambiando las relaciones de género, el reconocimiento de minorías sexuales, políticas sociales adecuadas a los grupos de edad: jóvenes, adultos mayores, e incluso la libertad de migración. Un conjunto de temas que nutren la agenda que vincula democracia y desarrollo, pero que no tiene su correlato en procesos de integración regional, por su incapacidad institucional para diseñar dispositivos para la persona en sus acuerdos supranacionales.

- Giro eco-territorial impacta negativamente a países y regiones de Latinoamérica y el Caribe. El regreso al modelo primario exportador, en su versión neo-extractivista opera contradicciones insalvables entre democracia y desarrollo. Aunque existen potencialmente ordenamientos legales para regular el impacto ambiental del crecimiento económico, estos son insuficientes para detener la depredación causada por la minería, las represas, los biocombustibles y la modificación biogenética de los cultivos. Coexisten una integración silenciosa de esas actividades, que no está dentro del marco de políticas públicas democráticas, con grandes ausencias en la normatividad dentro de los procesos de integración regional en curso.

\section{Instituciones globales, supra}

\section{y subnacionales en la nueva gramática democrática}

Desde que inician los procesos de integración regional ha habido grandes transformaciones del régimen político, del gobierno y del Estado en la región. Los debates giran en torno del imaginario democrático y sus versiones de pretendidos alcances universales, con las experiencias de transformación y adaptación de un imaginario democrático propio de nuestra ecología política: nuestro universal-particular.

- Carta y cláusula democrática. Entre el chantaje y el sesgo marcado por el interés de las potencias de los países centrales, se discute sobre 
la relación entre integración y democracia. Pero también hay registros originales en nuestra región, pues más allá de la visión sesgada de otros bloques de integración regional como la Unión Europea, u otros organismos del Pacífico asiático, algunas instituciones producto de la integración regional latinoamericana, han recreado creativamente ese debate, al incorporar en esas instituciones contenidos del imaginario democrático que orientan sus políticas nacionales y supranacionales.

ـ Consejos de Estado. Si bien la formación de la Celac apunta en su horizonte una integración regional de carácter comunitario, estamos lejos de esa posibilidad. La heterogeneidad de los bloques de integración que vive la región, las antinomias y contradicciones entre las distintas apuestas por el peso que se da a la integración económica, dominada por el comercio, conspira contra una integración democrática. A pesar de ello, algunos bloques como Mercosur-CAN o la Unasur, están creando una nueva institucionalidad en lo que hace a la división de poderes, la cual como se ve más adelante, no está sancionada por prácticas democráticas republicanas. Es el caso de la IIRSA, que promueve mega proyectos de desarrollo que implican coordinación entre los poderes Ejecutivos de los países miembros; una suerte de Consejo de Estado, pero que no cuenta con la debida aprobación de los parlamentos respectivos.

- Cultura parlamentaria incipiente, aún fragmentada. Sin una democracia de calidad que mejore la calidad de la representación política, los procesos de integración propician la existencia de Parlamentos supranacionales: el Andino, el del Mercosur, el de la Amazonía, el Centroaméricano y, en la lista, el Parlamento de la Unasur. El Parlatino, prácticamente inexistente e ineficaz, juega un rol simbólico sobre la necesidad de un Parlamento latinoamericano. ¿Circunscripciones propias o delegación de representantes a partir de los Parlamentos nacionales? No hay una definición clara al respecto, en el caso de la integración regional y de la aspiración a la unidad latinoamericana.

- Autonomías regionales; indígenas y culturales. La influencia del imaginario político liberal occidental impide que se reconozcan las comunidades políticas: una población, un territorio, una forma de gobierno, de aquellos grupos cuya formación antecede al Estado de Derecho y que no comparte la visión de ciudadanía individualista de un ciudadano un voto. Aunque la integración regional parezca ajena a estos grupos, su incorporación a ese proceso está sometida por la dinámica 
del mercado y una globalización sobre la cual se plantean demandas de autonomía por parte de estas comunidades políticas otras. Sin embargo, su ecología de saberes y formas de autogestión, no encuentran eco en el Estado nacional, ni tampoco en las nuevas instituciones supranacionales regionales.

\section{Ciudadanía y movimientos sociales}

Vinculados con el tema de las autonomías étnicas regionales, la ciudadanía múltiple y diferenciada, los movimientos sociales encierran una tensión permanente entre el papel instituyente que contienen y lo público instituido. Las relaciones entre Estado y sociedad se transforman gracias a esta tensión, y en el centro del debate sobre la nueva gramática democrática está el juego de poderes y contrapoderes, desde el mundo de vida de lo cotidiano hasta el cuestionamiento sobre lo prescindible de la estatalidad. Raúl Zibechi (2013), se pregunta si el Estado puede ser lo común, garante y depositario de los bienes comunes, pues justamente la configuración del interés comunitario caracteriza a los movimientos sociales.

El autor citado se plantea tres aspectos a discutir en torno de esa conflictiva relación entre Estado y movimientos sociales: uno, que el grueso de los movimientos latinoamericanos migraron de las posiciones autónomas a las prácticas estatistas y electorales. Dos: ¿puede el Estado, que no es lo común sino la expresión de una clase social, tener alguna utilidad para proteger lo común? Tres, en los últimos años hay un falso predicamento, expresado por los gobiernos progresistas recientes: si asumir la administración del Estado, el gobierno, es el único camino de transformación social. Anclado en escalas socioespaciales que son también escalas sociopolíticas, David Harvey señala la insuficiencia del poder comunitario en los asuntos supranacionales y globales que necesitan coordinación entre gobierno y sociedad, esto es el Estado. En este sentido, De Sousa Santos (2009), hace una proposición audaz: el Estado es el novísimo movimiento social del siglo XXI. Un planteamiento adecuado para comprender la emergencia de una nueva gramática democrática relacionada con la integración regional, pues si bien lo común es constituyente de la acción colectiva, el juego y cambio de escalas que produce la integración supranacional requiere de otra visión que no sea estatolátrica ni sólo comunitarista. De cualquier manera, la tensión Instituyente-Instituido, no puede cesar en la medida del permanente desajuste entre poderes y contrapoderes.

Pierre Rossanvallon (2007) sitúa el rol de la contrademocracia que paradójicamente incide en la democratización. Pues la conformación de los actores con capacidad de transformar su realidad se expresa en cualidades propias de la acción colectiva: 
๑ Capacidad de supervisión. El cuidado de los derechos humanos, la demanda por transparencia, rendición de cuentas y ejercicio responsable del Estado de Derecho, son acciones que desempeñan los movimientos sociales de manera autónoma. La calidad de la nueva gramática democrática opera en las múltiples escalas, desde los gobiernos locales hasta la dimensión global que pasa por la creación de regímenes internacionales. De ahí que estas capacidades que se anotan están ya presentes en el acotamiento de los procesos de integración regional.

- Capacidad de impedimento. El carácter excluyente y depredador de la fase neo-extractivista por la que pasa Latinoamérica, choca con redes de organismos sociales cuyos intereses no son defendidos por el Estado. Igualmente, la violencia punitiva del Estado sobre los pobres, cuenta con movimientos que están impidiendo que se les criminalice y pugnan por que sus demandas cobren visibilidad. La integración regional juega en pistas ambiguas: por un lado refuerza la capacidad interestatal de impedimento frente a las tendencias hegemónicas, pero por otra parte, sus políticas e instituciones supranacionales son impedidas de actuar por quienes se ven afectados, como es el caso del Tipnis en Bolivia o del Parque Yasuní en Ecuador.

- Capacidad juiciosa y crítica. El paso de los movimientos sociales hacia lo político, lo estatal y lo electoral, contribuye a la democratización de espacios locales y nacionales. Recientemente, esta politización de los movimientos sociales también contribuye a democratizar los espacios supranacionales y mundiales que emergen al calor de la integración regional. La coalición entre técnica y política permite argumentos sólidos para cuestionar procesos que se plantean como los únicos posibles.

Si hay algo positivo en los procesos de integración regional ello se debe, en buena medida, a los movimientos sociales que supervisan, impiden lo negativo y se lanzan a probar nuevos caminos, como alternativas juiciosas y críticas. Agrupaciones como la Alianza Social Continental, las Cumbres de los Pueblos, la Minga en Movimiento, el propio Ejército Zapatista de Liberación Nacional, o El Alba de los Movimientos Sociales; múltiples redes, asociaciones y organismos del más diverso tipo y con bases sociales étnicas heterogéneas, recubren de actividad colectiva al mapa latinoamericano. Pero en todos esos movimientos la integración y la democracia aún no forman parte de su agenda prioritaria. Falta que las iniciativas interestatales y la sociedad civil de los muchos se acerquen, y contribuyan a escribir y actuar en la nueva gramática democrática. 
Abstract: The "market's democratization and the liberal democratization's" purpose it's to soften the systemic and global crisis of Latin America, a region whose historical memory registers harsh processes of market authoritarianism over its political systems. The procedural democracy and the multiparty political system monopolize the representation, pretending to be the cure against authoritarianism and source of a future prominent development. In the mean time, the neo-liberal speech praised the advantages of the free market, the no regulation, the privatization and based on the Washington Consensus established this ideological model as the conductor for the integration and the condition for the democratic and macroeconomic stability. Never the less, the liberal-procedural democracy in the region, associated to the neo-liberal integration process, produced a conflictive triangle State-Society-Market where the imposition of a particular model of political organization and a homogenous American European system of values promoted as global democracy was the main speech. As a response to the inequity and segregation produced from this model, new post-neo-liberal approaches emerge oriented to re-think the democratic integration in a Latin-American context. From the social movements, political projects raise with a new democratic grammar of resistance and the acknowledgement of social agendas oriented to an autonomous Latin-American integration.

Key words: democracy, regional integration, social movements, autonomy.

\section{Referencias generales}

AlPíZAR, Guillermo L. Andrés. Ocho desafíos para la integración latinoamericana y un nuevo rol para Asia. Alai AmLATINA, 25/09/2012, consultado el 8 de junio de 2013, en: $<$ http://alainet.org/active/58183>.

AVRitzer, Leonardo. Las instituciones participativas en el Brasil democrático. México: Universidad Veracruzana, 2010.

Crozier, Michel: Huntington, Samuel J.; Watanuki, Joji. The Crisis of democracy (Crisis de la democracia: reporte sobre la democracia y la gobernabilidad). Comisión Trilateral, ONU. New York: University of New York, 1975.

DE LA GARZA, Toledo. Neoinstitucionalismo, ¿̇opción ante la elección racional? Una discusión entre la Economía y la Sociología. Revista Mexicana de Sociología, v. 67, n. 1, México, Enero-Marzo, 2005, p. 163-203.

De Sousa SANTOS, Boaventura. Democratizar a democracia. Os caminhos da democracia participativa. Porto: Edições Afrontamento, 2003.

. "Capítulo I. La sociología de las ausencias y la sociología de las emergencias: para una ecología de saberes". In: Renovar la teoría crítica y reinventar la emancipación social (encuentros en Buenos Aires). CLACSO, Buenos Aires, Agosto 2006. Disponible en: <http://bibliotecavirtual.clacso.org.ar/ar/libros/edicion/santos/Capitulo\%20l.pdf>.

drid: Ed. Reinventar la dentur, 2009. 
Gohn, Maria da Glória; BRINGeL, Breno (Eds.). Movimentos sociais na era global. Petrópolis: Vozes, 2013.

González Casanova, Pablo. La dialéctica de las alternativas. Revista Casa de las Américas, n. 226. Cuba, Enero-Marzo, 2002.

HARVEY David. El nuevo imperialismo. Acumulación por desposesión. In Socialist Register 2004: El nuevo desafío imperial, Buenos Aires, Biblioteca Virtual de CLACSO, 2004.

MARTIns de Albuquerque, Paulo Henrique Novaes. La decolonialidad de América Latina y la heterotopía de una comunidad de destino solidaria. Buenos Aires: Fundación CICCUS/Estudios Sociológicos Editora, 2012.

Morlino, Leonardo. Observando las diferentes calidades de la democracia. Revista Mexicana de Análisis Político y Administración Pública, n. 1. México, 2012, p. 9-48.

NARANJo Morales, Andrea Del Pilar. Integración regional y democracia en América Latina y el Caribe. Revista Electrónica Iberoamericana, v. 6, n. 2, 2012. <http://www.urjc. es/ceib/>.

O'DONNELL, Guillermo; SCHMITTER, Philippe C.; WHITEHEAD, Laurence. Transitions from authoritarian rule: comparative perspectives. 3 v. Washington, DC: The Woodrow WiIson Center for Scholars, 1986.

PNUD. La Democracia en América Latina. Hacia una democracia de ciudadanas y ciudadanos. 2. ed. Buenos Aires: Aguilar, Altea, Taurus, Alfaguara, 2004.

PRECIADO Coronado, Jaime. Escenarios posneoliberales frente a la VI Cumbre de las Américas. Revista InterNaciones. México: Universidad de Guadalajara, 2013.

QuiJano, Aníbal. Colonialidad del poder, eurocentrismo y América Latina. In La colonialidad del saber: eurocentrismo y ciencias sociales. Perspectivas Latinoamericanas. Edgardo Lander. Buenos Aires: CLACSO, Consejo Latinoamericano de Ciencias Sociales, Julio de 2000. p. 246. Disponible en <http://bibliotecavirtual.clacso.org.ar/ ar/libros/lander/quijano.rtf>.

REIFER, Tom. Giovanni Arrighi, la larga duración del capitalismo geohistórico y la crisis actual. Viento Sur, Revista Rebelión, 2009. Disponible en: <http://www.rebelion.org/ noticias/2009/9/91955.pdf>.

Rosanvallon, Pierre. La contrademocracia: la política en la era de la desconfianza. Buenos Aires: Ed. Manantial, 2007.

SADER, Emir. 10 anos de governos pós-neoliberais no Brasil: Lula e Dilma. São Paulo: Boitempo, FLACSO, 2013. 
StIGlitZ, Joseph. El consenso post-consenso de Washington. Washington, DC: The Initiative for Policy Dialogue, 2008.

SVAMPA, Maristella. Imaginario desarrollista, giro eco-territorial y cuestión ambiental. Apunte de Cátedra Debates Latinoamericanos: Ideas, Escenarios y Categorías en Disputa. Argentina: UNLP, 2010.

UGARTECHE Oscar y Ariel Noyola Rodríguez. Las tres velocidades de la crisis y su bifurcación. Buenos Aires: Agencia Latinoamericana de Información, 2013. Disponible en: $<$ http://alainet.org/active/63742>.

WACQANT, Loïc. Três etapas para uma antropologia histórica do neoliberalismo realmente existente. Caderno CRH, v. 25, n. 66, p. 505-518. Salvador, Set./Dez. 2012,

WILLIAMSON, John (Ed.). Latin American Adjustment. How much has happened? Washington, DC: Institute for International Economics, 1990.

Williamson, John; KuCZINSKY, Pedro Pablo. After the Washington Consensus: Restarting Growth and Reform in Latin America. Washington, DC: Peterson Institute for International Economics, 2003.

ZIBECHI, Raúl ¿Puede el Estado ser lo común?” Diario La Jornada, México, 22 Marzo 2013. 